\title{
MEXICO'S SCIENTIST IN CHIEF
}

\author{
After winning a Nobel prize for helping to protect the \\ planet, Mario Molina is tackling a much more difficult \\ problem - trying to clean up Mexico City.
}

\section{BY JEFF TOLLEFSON}

$\mathrm{C}$ ab drivers have heard of him. Political leaders seek his advice. Strangers often shake his hand in a mixture of congratulations and thanks. Such is the fame of Mario Molina, the 67-year-old chemist who has become something of a national icon in his hometown of Mexico City.

More than four decades ago, Molina left this city to pursue his doctorate in the United States. His first paper as a postdoc in 1974 alerted the world to the atmospheric dangers of chlorofluorocarbons (CFCs), and helped to save the ozone layer - the planet's shield against ultraviolet radiation. Molina went on to win the Nobel Prize in Chemistry and rise to the top ranks at the Massachusetts Institute of Technology (MIT) in Cambridge. But close personal and cultural ties pulled him back to Mexico City some five years ago, when he shifted away from the elegance of stratospheric chemistry to tackle the messy world of public policy, urban planning and climate change.

Molina's great challenge is to help Mexico City to reach its goal of becoming the greenest megacity in Latin America. It is a tall order. This metropolis of more than 20 million people was once considered the most polluted urban area in the world. Mexico City made great strides during the years that Molina was in the United States, and he has pushed for further environmental gains since his return. But the city still suffers from problems such as persistent air pollution, rampant development and poor sanitation.

Through his eponymous think tank, the Mario Molina Center for Strategic Studies in Energy and the Environment in Mexico City, Molina has assembled a team to tackle those seemingly intractable problems. As the only Mexican to garner a science Nobel, Molina uses his stature to provide behind-the-scenes advice to government and industry leaders. Some think he should take a more forceful stand on issues, but Molina's quiet style has already earned him the trust of Mexico City's mayor, Marcelo Ebrard, as well as Mexican President Felipe Calderón. This is Molina's way of giving something back to the country that provided him with opportunities as he grew up. "The Nobel prize is of course a big honour and so on, but it's also a responsibility," he says. "If I use it wisely, then I can impact government decisions."

\section{IT'S LIKE GOSPEL}

Molina grew up in an atmosphere of culture and privilege, with a father who tripled as a successful lawyer, academic and diplomat. Mario travelled the world for his education, attending boarding school in Switzerland, university in Mexico and Germany, and graduate school at the University of California, Berkeley. All this helped him to develop an international view on the world and a diplomatic personality. Although accustomed to advising lawmakers, governments and heads of state on difficult issues, he does not flaunt his status.

"Mario conveys overwhelming modesty and humbleness," says Adrián Fernández Bremauntz, a long-time colleague and friend who heads the National Institute of Ecology, a research arm of the federal environment ministry, based in Mexico City. Some people invoke the term "Saint Mario", and Fernández jokes that he can almost make out a halo above Molina's head when he speaks. "It's like gospel."

After winning his Nobel prize in 1995, Molina took advantage of his academic freedom as an institute professor at MIT and began rethinking his scientific agenda. In 1999, he and his first wife, and long-time research partner, Luisa Molina established the Integrated Program on Urban, Regional and Global Air Pollution at MIT. Their goal was to study megacities, and the first case was Mexico City.

By that time, the city had already cleaned up its act considerably. From the 1980s to the late 1990s, the city had phased out the use of leaded petrol and had reduced sulphur levels in diesel fuel, while shifting power plants and industry away from diesel and fuel oil towards IS CHOOSING THE RIGHT PROBLEM, BUT THEN YOU NEED TO TAKE ADVANTAGE OF IT."
"PART OF THE LUCK cleaner-burning natural gas. It had also phased in the use of catalytic converters and other pollution-reduction technologies for new vehicles.

But pollution levels above the city were still formidable. In 2003 and 2006, the Molinas organized a pair of intensive air-sampling campaigns involving hundreds of scientists from several US, Mexican and European institutions ${ }^{1}$. The campaigns have generated more than 170 publications so far, and today scientists have more data about Mexico City's air pollution than about any other city in a developing country - and perhaps the world.

The picture that emerges could be likened to a bubbling cauldron. Mexico City is built on a plateau 2,240 metres above sea level, where abundant ultraviolet radiation cooks up a stew of pollution. It includes black carbon, sulphur and nitrogen oxides from vehicles, and volatile organic compounds (VOCs), which come from sources such as vehicles, leaking gas canisters, solvents and paints (see 'Sources of air pollution of Mexico City', page 905). The reactions between nitrogen oxides and VOCs form ozone, a potent constituent of smog that often gets trapped above the city by the surrounding mountains and temperature inversions.

The air-sampling campaigns showed that, contrary to expectations, VOCs rather than nitrogen oxides control how much ozone forms above the city. With that in mind, the authorities are expanding the metropolitan area's pollution regulations to also target VOC emissions from specific sources. "In the past, we didn't pay very much attention to controlling solvents," says Victor Hugo, who heads the city's airquality programme. "Now we consider them as part of the principal 


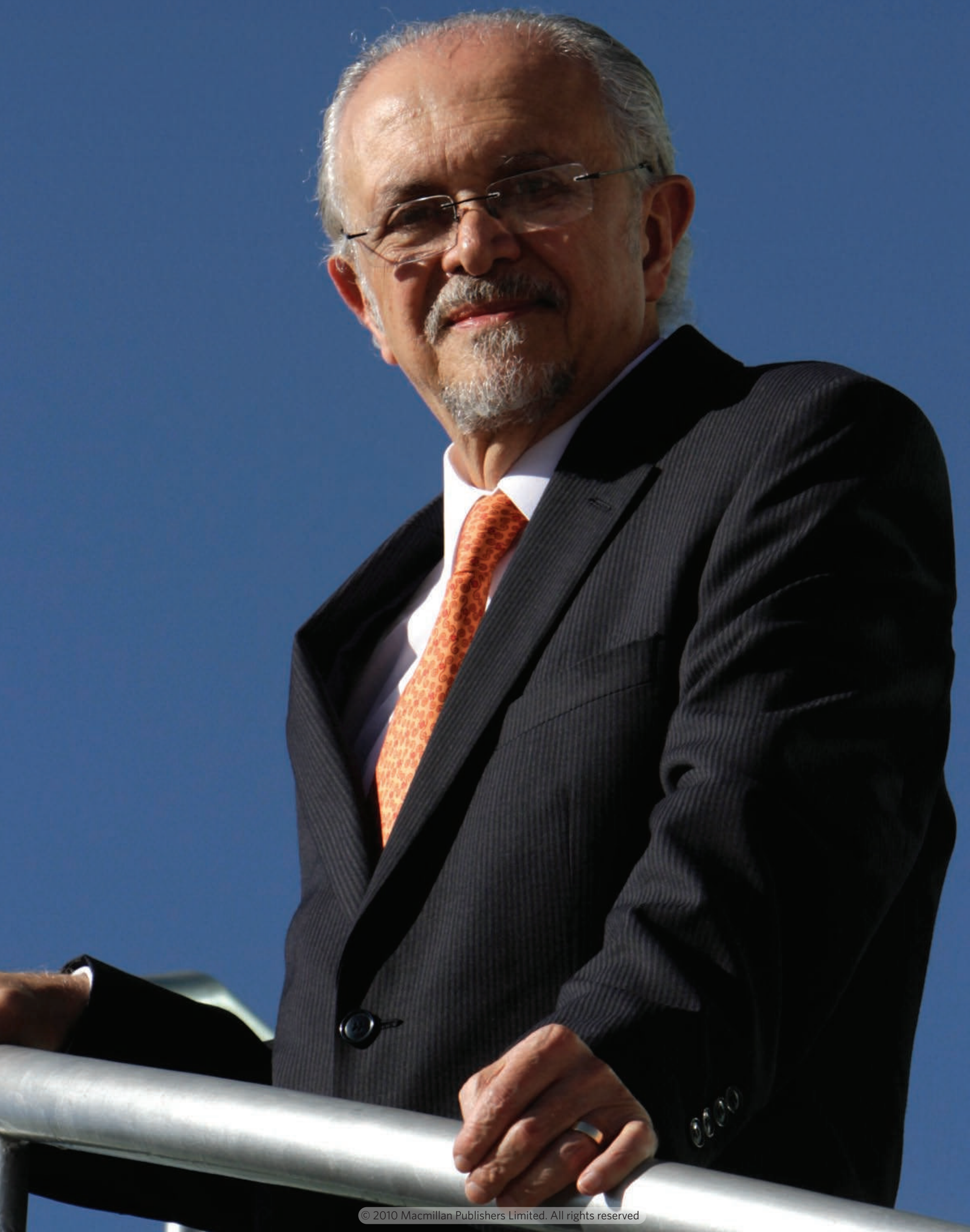




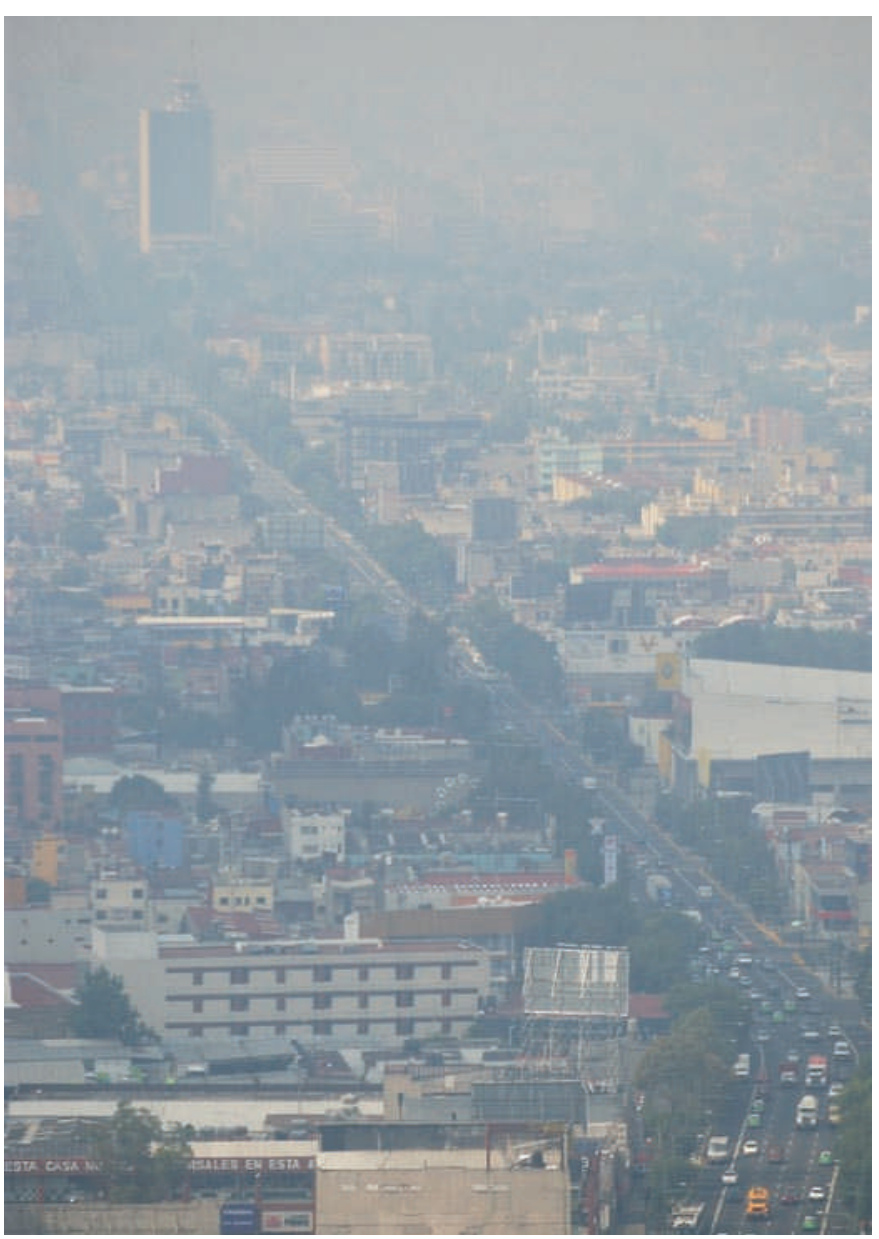

Mexico City still has excessive smog despite policies to reduce pollution.

> measures in the new air-quality priorities that are being designed." In 2004, the Molinas moved to the University of California, San Diego, but the couple eventually went separate ways, both personally and scientifically. Luisa continues their megacities work in San Diego at her own institute named the Molina Center for Energy and the Environment. Mario moved back to Mexico City, where he took up the fight to combat smog by reducing the sulphur concentrations in fuels. Fernández says that Molina provided a crucial voice by keeping air quality on the agenda at a time when political momentum was flagging - precisely because city and federal authorities had already made so much progress. The continued pressure from Molina and others helped to convince authorities to expand the use of low-sulphur petrol and diesel - much of which has to be imported from other countries. Now that the quality of fuel is improving, says Hugo, Mexico is contemplating new air-pollution and fuel-efficiency standards for vehicles.

Molina takes heart from these accomplishments, but plays down his own role. "It took a huge effort on the part of many people," he says, "and those partnerships continue today."

The centre in Mexico that bears Molina's name is housed in a modern office tower, perched on a hill on the west side of town. Guillermo Velasco, project coordinator at the centre, gestures out of the window towards sets of buildings that have sprouted in the past decade "The city is growing horizontally," says Velasco, who met Molina in Cambridge, while studying public policy at Harvard University. "It's not sustainable."

Many cities around the world have encountered similar problems, Molina says, but Mexico City faces the added burden of widespread corruption, pockets of stifling poverty and limited government resources to turn things around. Once established, illegal shantytowns are hard to control. And even in wealthier areas, construction companies clear cheap land and build at will. "If you had a good city plan and you

designed the legal measures so that you can enforce them," says Molina "that wouldn't happen."

He established his think tank to help craft the policies that could make Mexico City more sustainable. The centre started out small, made up of Molina and several colleagues from his university days in Mexico and Berkeley. Some of its initial funding came from the William and Flora Hewlett Foundation based in Menlo Park, California, and from Carlos Slim, a Mexican telecommunications magnate. Over the past five years, the centre has expanded to roughly 45 people, including environmental engineers, architects, urban planners and biologists.

The team is pushing for policy changes on several fronts. It supports expansions in public transport, more mixed-use neighbourhoods that allow people to live close to their work, changes to the tax code to discourage sprawl and ways to integrate planning with the various levels of government. Molina and his team are producing a series of regional sustainability studies, the first of which is expected early next year.

These and other efforts are intended to help authorities to conduct a broader environmental agenda, including meeting the city's goal of reducing greenhouse-gas emissions by 12\% between 2008 and 2012. Climate change has recently emerged as a priority in Mexico. Ebrard chairs the World Mayors' Council on Climate Change and will host a climate meeting in Mexico City on 21 November, a week before the international climate summit in Cancún, Mexico.

But the Molina centre hasn't been free of criticism or controversy. There have been concerns about the centre doing consulting work for industrial interests such as PEMEX, Mexico's state-owned oil company, rather than focusing on its own independent agenda. Molina is also pulled all over the world by his many international commitments, including serving on US President Barack Obama's Council of Advisors on Science and Technology as well as a part-time academic post at the University of California, San Diego. Funders and members of the advisory board, including Fernández, have urged Molina to take a more active role in guiding the centre.

Molina acknowledges these criticisms and is working on a strategic review of the centre. He says that the centre has never compromised its findings when working with industry - which he views as necessary and important - but is nonetheless moving away from paid consulting. The Mexican Congress made that move easier by allocating $50 \mathrm{mil}$ lion pesos (US\$4 million) to the centre in 2010, roughly doubling the centre's annual budget.

\section{THE MARIO MOLINA BRAND}

"The Molina centre has the potential to be one of the two or three most credible institutions in developing countries on energy and environmental policy," says Joseph Ryan, a former programme officer at the Hewlett Foundation, which provided about \$ 4 million in funding to the centre from 2004 to 2009. But Ryan says that the centre is too closely linked with its founder and must take care to develop its own credibility "independent of the Mario Molina brand".

Molina started building that brand when he arrived at the University of California, Irvine, for his postdoctoral fellowship with Nobel-prizewinning atmospheric chemist Sherwood Rowland in 1973. Rowland offered him several projects, most of which centred on his own analyses of radioactive molecules, but the list contained one outlier: an investigation into the fate of an increasingly important class of commercial chemicals - CFCs - used as refrigerants and propellants in aerosol cans. Rowland thought that the compounds could be useful as tracer chemicals for atmospheric research. Molina chose the CFC project, attracted by the possibility that his work could have real-world implications.

"He certainly picked the right project, and was of course instrumental in working it through," says Rowland. "At the end of three months,

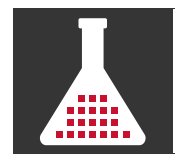
SCIENCEANDTHE CITY Full content and enhanced graphics at: nature.com/cities we realized that we had the bear by the tail."

CFCs were popular in commercial products because they did not seem 


\section{SOUREESOF AIR POLLUTION WMEXXEOCTIY}

The complex brew of chemicals includes volatile organic compounds (VOCs) and nitrogen

oxides $\left(\mathrm{NO}_{x}\right)$, which react to form damaging tropospheric ozone. Sulphur dioxide $\left(\mathrm{SO}_{2}\right)$, another

harmful compound, comes from the combustion of sulphur-laden fuels and other sources.

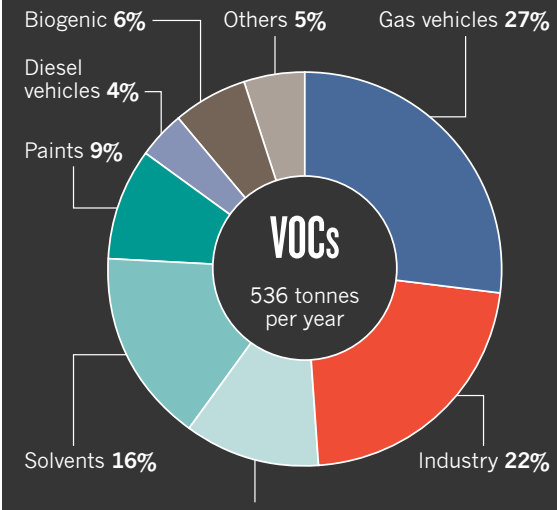

Liquified petroleum gas leaks $11 \%$

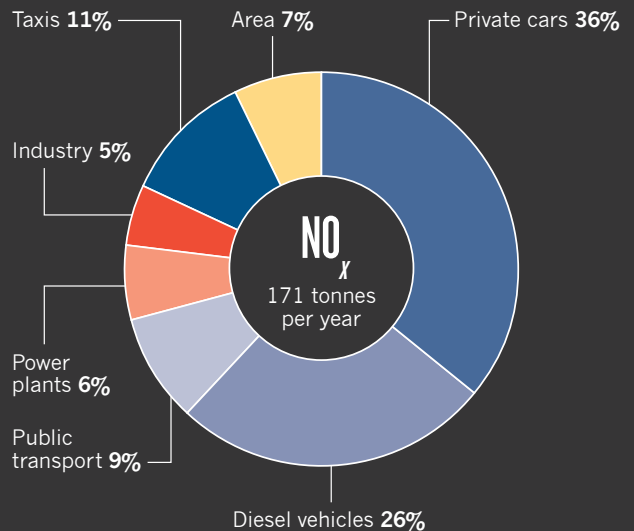

Diesel vehicles $\mathbf{2 6 \%}$

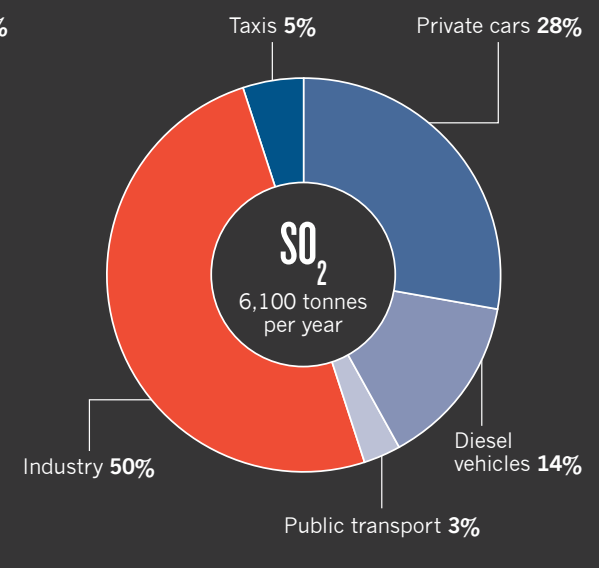

to react with other gases. Recognizing that the chemicals would gradually collect in the stratosphere, the two calculated that CFCs would in fact break down under a combination of cool air and the harsh ultraviolet radiation of the upper atmosphere. Those reactions would liberate chlorine atoms that could then crack ozone molecules. Molina and Rowland published their findings in Nature ${ }^{2}$ in June 1974.

That work helped to spur the United States to ban the use of CFCs in aerosol cans in 1978, and eventually led to a global phase out through the 1987 Montreal Protocol on Substances that Deplete the Ozone Layer. The 1974 paper with Rowland also served to focus Molina's research. Studying the atmosphere would allow him to pursue his interests in fundamental chemistry, "but it was also very close to an applied field", he says.

In 1985, British researchers showed that ozone over Antarctica was disappearing every spring ${ }^{3}$ far faster than could be explained by the reactions proposed by Molina and Rowland. Mario and Luisa Molina, who had since moved to NASA's Jet Propulsion Laboratory in Pasadena, California, joined the race to explain the ozone hole. "He was one of the more gentle creatures in that fight," says Michael Prather, an atmospheric chemist at the University of California, Irvine.

Two years later, the Molinas and their colleagues cracked the problem, proposing a pathway that recycles chlorine molecules so that they can repeatedly destroy ozone. The process starts with a chlorine atom stealing an oxygen atom from an ozone molecule $\left(\mathrm{O}_{3}\right)$ to form chlorine monoxide. That highly reactive compound reacts with itself to form a dimer, $\mathrm{Cl}_{2} \mathrm{O}_{2}$. When spring arrives in Antarctica, sunlight shears off the oxygen, freeing up two chlorine atoms to repeat the reaction in a runaway cycle ${ }^{4}$.

Although Molina won the Nobel prize for his 1974 work, some scientists regard this later discovery - made when the research community was racing for a solution - as the one that really lit up Molina's scientific credentials. Molina chalks his success up to a little luck, intuition and a lot of hard work. "Part of the luck is choosing the right problem," he says, "but then you need to take advantage of it."

Prather says that Molina has a keen ability to step back from the detailed chemistry and think about the larger problems that affect society. He wasn't surprised when Molina turned his attention to the skies above Mexico City. "We all knew that deep in his heart his ties were to Mexico."
In early September, Molina delivered a 45-minute keynote lecture about climate change to financiers at the Mexican Banking Association in Mexico City. This event was co-organized by the United Nations Environment Programme Finance Initiative in advance of the November climate summit. Molina covered the science of climate change without stepping over the line into advocating specific policies, as some researchers have started to do. After the talk, Burghard Petersen, a former banker and climate consultant from Germany who has lived in Mexico for 19 years, said that Molina "is offering credibility. He's not a sales person."

But some think he should be selling his ideas harder. "Mario has chosen a very friendly, moderate, constructive approach," says Fernández. "If he wants to accomplish his goals, I would certainly advise him to grab the government's neck every once in a while and be more pushy."

\section{COOL ADVICE}

Back in his office, Molina says that he prefers to build coalitions from the inside rather than using the press and his position of authority to pressure decision-makers into action. He is careful not to reveal his own politics and has built up relations with parties on both sides of the Mexican political spectrum. Questions about the environment are far less partisan in Mexico and many other developing countries than they are in the United States, and Molina wants to keep it that way.

On the wall behind Molina's orderly desk hangs a watercolour painting of an open umbrella in muted tones, a gift from the Nobel committee symbolizing the protective ozone shield that Molina helped to save. He acknowledges that the social and political problems he is working on now are not likely to yield as easily to a solution as the stratosphere did. Some days he can see out of his window all the way to the centre of Mexico City, but today smog fills the vista, a dramatic indication of how much work remains to be done.

An optimist at heart, Molina takes the long view and says civilization is improving on the whole. Only 500 years ago during Aztec times, he notes, people were sacrificed at the top of the temple downtown.

"That would be inconceivable today," he says with a chuckle. "I'm not naive. I know it's going to take time, but we are taking on part of the challenge and doing the best we can." a SEE EDITORIAL P.883

Jeff Tollefson is a reporter for Nature based in Washington DC.

1. Molina, L. T. et al. Atmos. Chem. Phys. 10,8697-8760 (2010).

2. Molina, M. J. \& Rowland, F. S. Nature 249, 810-812 (1974).

3. Farman, J. C., Gardiner, B. G. \& Shanklin, J. D. Nature 315, 207-210 (1985)

4. Molina, L. T. \& Molina, M. J. J. Phys. Chem. 91, 433-436 (1987). 